\title{
How should I prepare for a consultant interview?
}

\author{
Consultant interviews can be daunting, but preparation is the key to success, Abi Rimmer hears
}

\section{Abi Rimmer}

The BMJ

\section{You're joining a family}

Julie-Ann Maney, a consultant in paediatric emergency medicine in Belfast, says, "This interview is the culmination of years of training. The best advice I was given as a junior, and the advice I still offer, is "the training scheme is the longest interview you will ever do."

"When you join a consultant team you are joining a family and you'll have to fit in. The trust or health authority want you to be able to do the job. Your new colleagues want that too but, more importantly, they want to know if you're a nice, kind, and reasonable person. Will you have their backs when they need you? Will you swap into a Friday night on call because they have a family emergency?

"Be prepared for the interview. Know the management structure and the who's who of hospital bureaucrats. Meet the clinical director or whoever is stated in the advertisement. Consider a mock interview with someone who'll be brutally honest and constructive with their feedback. On interview day, dress to impress, take your time, and show the panel how you are going to add value to the organisation. The interview is the time to blow your own trumpet and blow them away."

\section{Meet the panel in advance}

Perbinder Grewal, consultant vascular surgeon at the University Hospital Southampton, says, "Preparation for the interview is key and it's imperative that you research the job and the hospital. This can take many forms, from ringing the registrar on call to researching the trust on Google. Each trust will have information on their website, such as annual accounts, minutes from annual meetings, and recent Care Quality Commission reviews. These will give you a good overview of the trust's health and help you understand the local issues. If your specialty has a national outcomes registry, this will show you where the trust sits nationally. It's also important to make sure that you're happy with the job plan that's being offered.

"A pre-interview visit to the hospital is mandatory-you will be able to look around and meet the staff. Your shortlisting letter should give you a list of all the members of the appointments advisory committee. You need to try to visit most, if not all, before the interview. Try to gauge what they are looking for in the candidate. The questions you may want to ask could be regarding the trust's future strategy and the specialty's position within that. If you're giving a presentation on the day, ensure that it is focused on the job you are applying for with data from the trust.

"Try to rehearse common questions with consultants who regularly interview to gain feedback. You must be ready to talk positively about yourself as a doctor and as a future colleague."

\section{Spend time getting it right}

Rebecca Lawrence, consultant psychiatrist and clinical director for NHS Lothian, says, "Preparing for a consultant interview may be one of the most important things you ever do. Treat it with respect and don't be afraid to spend time, and even money, on getting it right. There's a fine balance between over and under preparing for the actual interview. Consider an interview course, particularly if you are anxious. Or practise with a friendly colleague.

"On the day wear something smart but comfortable. Ask for water (it should be offered). Try to look at everyone in turn.

"Be prepared for the easy questions-why you want the job, why they should employ you, and what you are good at. The hard ones will be hard anyway, but if you know your stuff and take your time, you will manage.

"This is not the time to be modest—which may be difficult if you personally know one of the panel. If you come out squirming at your own boastfulness, it may actually have gone extremely well.

"There will be factors that you cannot influence, like bad luck, being unwell on the day, or an exceptionally good local candidate. If you don't get the job, allow yourself a bit of time, get feedback, and move on. There is no one right job, and there will be another one for you."

\section{Tackle your weaknesses}

Emily Henderson, consultant geriatrician at the Royal United Hospitals NHS Foundation Trust, says, "Consultant interviews mark a key transition point in our lives and careers, and therefore it's unsurprising that people approach the preparation process with trepidation. But the process is no secret. When the invitation for the interview arrives, find out who is on the panel and who it would be appropriate to meet. Use these meetings as pre-interviews. Ascertain what problems the trust is facing and think about how you can help solve them. Listen more than you speak, but make a positive impression. 
"New consultants are your friends and potentially your colleagues. Ask them what their experience of the interview was. If you have to do a presentation, keep it simple and don't overly animate your slides. Practise it daily to medics and non-medical friends.

"On the day, turn up. Skype is not ideal and nor is teleconferencing as you can't judge responses or body language. Dress smartly, even if you live in scrubs normally. A firm handshake and a smile will get things off to a good start. Pause before you answer.

"You know yourself so proactively tackle your interview weaknesses, be that sweaty palms or rambling answers. Say exactly why you are the right person for the organisation and the department. In the latter stages, your concentration will falter because of the intensity of the process-save $10 \%$ for that last question.” 